\title{
Editorial: Smart Materials for Energy Conversion and Sensor Based Technologies
}

\author{
Mahendra Dashrath Shirsat ${ }^{1 *}$, Bhaskar R. Sathe ${ }^{1}$ and Pankaj Madhukar Koinkar ${ }^{2}$ \\ ${ }^{1}$ Department of Physics, Dr. Babasaheb Ambedkar Marathwada University, Aurangabad, India, ${ }^{2}$ Department of Optical \\ Science, Tokushima University, Tokushima, Japan
}

Keywords: smart materials, sensor, energy devices, catalyst, heavy metal

\section{Editorial on the Research Topic}

\section{Editorial: Smart Materials for Energy Conversion and Sensor Based Technologies}

It is a matter of great pride and gratification to come up with special issue of Frontiers in Materials: Smart Materials for Energy Conversion and Sensor Based Technologies.

Research articles covering the following topics (but not limited to) were invited for this special issue.

i) Nanomaterials for chemical and electrochemical sensors (gas, heavy metals, biomolecules, and other intermediates), energy conversion, storage, and utilization;

ii) Transition metal and carbon nanomaterials based photocatalysts and electrocatalysts;

iii) Electrochemical biosensors;

iv) Principle of electrochemical biosensors;

v) Electrochemical detection techniques;

OPEN ACCESS

Edited and reviewed by:

Weihua Li,

University of Wollongong, Australia

*Correspondence:

Mahendra Dashrath Shirsat mdshirsat@gmail.com

Specialty section:

This article was submitted to

Smart Materials,

a section of the journal

Frontiers in Materials

Received: 05 November 2020

Accepted: 04 March 2021

Published: 25 March 2021

Citation:

Shirsat MD, Sathe BR and Koinkar PM (2021) Editorial: Smart Materials for Energy Conversion and Sensor Based Technologies. Front. Mater. 8:626397. doi: 10.3389/fmats.2021.626397 vi) Potentiometric biosensors;

vii) Amperometric biosensors;

viii) Impedimetric biosensors;

ix) 2D material-based electrochemistry;

$\mathrm{x})$ Mechanism of electrochemical sensing in nanomaterials-based electrodes;

xi) Hybrid biosensors;

xii) Nanostructures, nanofabrication, and nanoprobes by electrochemical sensing modality.

Smart Materials are at the forefront of scientific and technological exploration today. Continuous pursuit toward an in-depth understanding of the structure, properties, and employability of such materials has led to hitherto untrodden horizons by synergistic involvement of multidisciplinary research areas. The wide spectrum of smart materials includes metallic materials, ceramic materials, polymeric materials, nanocomposite materials, and biomedical materials. Researchers working on nanomaterials, in the last two decades, have invaluably contributed in the fields of photocatalysts, electro-catalysts, lithium/sodium ion batteries, chemical sensors, supercapacitors, and their quantum of findings found successful technology conversions toward meeting continuously changing demands in the sectors of energy and environment.

The special issue of the Frontiers in Materials entitled Smart Materials for Energy Conversion and Sensor-Based Technologies has provided multidisciplinary research opportunity to present the results on the development in the field of smart materials for energy conversion and sensorbased technologies. This platform has played vital role in bringing prominent scientists, researchers, and scholars across the globe. 
Nanostructure based chemical sensors have a significant contribution to critical as well as trivial characteristics of science, engineering, and technology. The identification based on accuracy, sensitivity, and reliability of different gas species/volatile organic compounds is very much essential in various field, for example, industrial and agricultural plants, food sciences, or environmental monitoring. In the past decade, chemical sensors based on nanomaterials have attracted many research scholars throughout the world because of their extraordinary sensing performance. At the same time, various challenges in the form of sensitivity, selectivity, quick response, robustness, and additional aspects have kept aplenty windows open for research and development in the area of nanostructured chemical sensor devices. Technological advancement in the area of development of an improved and new version of equipments has provided excellent opportunities for the development of emerging materials for various applications. At the same continuous efforts need to be directed toward understanding the properties of various function materials and their processes. And fundamentally, knowledge on sensing mechanisms has to be highly improved by the help of sound theoretical models and advance probing tools e.g., spectroscopic technologies. This special issue has given special emphasis on the articles having an exploration of smart materials for energy conversion and sensor based technologies.
We are quite sure that this special issue will be playing a role catalyst to have a more extensive exploration of materials for various technological applications to address unresolved issues of society.

\section{AUTHOR CONTRIBUTIONS}

All authors listed have made a substantial, direct and intellectual contribution to the work, and approved it for publication.

\section{ACKNOWLEDGMENTS}

We sincerely thanks frontiers for allowing us edit the special issue.

Conflict of Interest: The authors declare that the research was conducted in the absence of any commercial or financial relationships that could be construed as a potential conflict of interest.

Copyright (C) 2021 Shirsat, Sathe and Koinkar. This is an open-access article distributed under the terms of the Creative Commons Attribution License (CC BY). The use, distribution or reproduction in other forums is permitted, provided the original author(s) and the copyright owner(s) are credited and that the original publication in this journal is cited, in accordance with accepted academic practice. No use, distribution or reproduction is permitted which does not comply with these terms. 